\title{
Characterization of tungsten tips for STM by SEM/AES/XPS
}

\author{
W. Lisowski ${ }^{2 *}$, A. H. J. van den Berg ${ }^{2}$, G. A. M. Kip ${ }^{1}$, and L. J. Hanekamp ${ }^{1,2}$ \\ ${ }^{1}$ Faculty of Applied Physics and ${ }^{2}$ Centre of Material Research, University of Twente, P. O. Box 217, NL-7500 AE Enschede, \\ The Netherlands
}

Received February 25, 1991

Summary. For the first time, both X-ray Photoelectron Spectroscopy (XPS) and Auger Electron Spectroscopy (AES) techniques were applied in analysis of surface contamination of electrochemically etched Scanning Tunneling Microscope (STM) tungsten tips. Carbon monoxide, graphite, tungsten carbide and tungsten oxide were found as main surface contaminations of STM tungsten tips. The thickness of tungsten oxide layers was estimated to be about $1-3 \mathrm{~nm}$. Quantitative analysis of surface and bulk concentration of carbon, oxygen and tungsten has been performed.

\section{Introduction}

One of the major experimental aspects of Scanning Tunneling Microscopy (STM) operation is the reliable and reproducible formation of tunneling probe tips. It is well known that the structure of the tip influences significantly the resolution of STM [1]. Furthermore, the tunneling current noise depends strongly on tip surface contaminations [2].

Only a few papers are dealing with the analysis of surface composition of STM tips. Transmission Electron Microscopy (TEM) studies indicated that the most widely applied tungsten tips, prepared by electrochemical etching, were covered by thin $(1-5 \mathrm{~nm}$ thick) polycrystalline tungsten oxides [3,4] and carbon or graphite [2] layers. X-ray Photoelectron Spectroscopy method was employed for the determination of graphite tip surface composition [5].

The purpose of this paper is the elucidation of chemical structure of electrochemically etched STM tungsten tip layers as well as the determination of the layer thickness. In order to realize these objectives, Auger Electron Spectroscopy (AES) combined with $\mathrm{Ar}^{+}$sputter profiling and X-ray electron spectroscopy (XPS) techniques were utilized.

\footnotetext{
* Permanent address: Institute of Physical Chemistry, Polish Academy of Sciences, ul. Kasprzaka 44/52, PL-01-224 Warszawa, Poland Offprint requests to: W. Lisowski
}

\section{Experimental}

Electrochemically etched tungsten tips were fabricated by placing some millimeters of $0.5-\mathrm{mm}$ cold drawn tungsten wire into an $1 \mathrm{~mol} / 1 \mathrm{KOH}$ etching solution and applying a $12 \mathrm{~V} \mathrm{ac}$ potential to the tungsten wire (with respect to a platinum ring electrode inserted into the solution). The etching process was discontinued when the suspended wire fell off. The wires were cleaned after etching with ultrasound in distilled water and isopropyl alcohol.

Figure 1 shows a Scanning Electron Microscope (SEM) image of a typical tungsten tip on which the analysis has been done.

AES measurements were performed with a PHI 600 SAM (Scanning Auger Microscope) system. The analyzed area was about $0.4 \mu \mathrm{m}^{2}$ at a primary beam energy $\mathrm{Ep}=10 \mathrm{kV}$, a beam current $\mathrm{Ip}=0.5 \mu \mathrm{A}$ and beam diameter of $0.7 \mu \mathrm{m}$. The resolution of the cylindrical mirror analyzer was set at $0.6 \%$.

Alternate sputtering and Auger analysis were used during an in-depth analysis. The argon ion beam with an ion energy of $3.5 \mathrm{keV}$ was produced by a differentially pumped ion gun. The sputter rate of tungsten oxide was found to be $4.3 \mathrm{~nm} /$

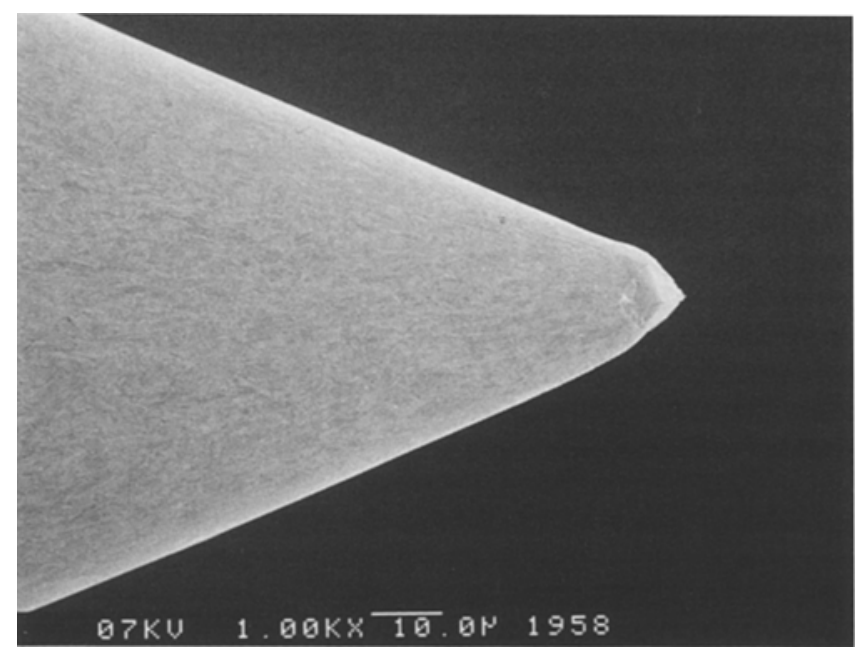

Fig. 1. Scanning Electron Microscope image of an electrochemically etched tungsten STM tip analyzed by AES and XPS 


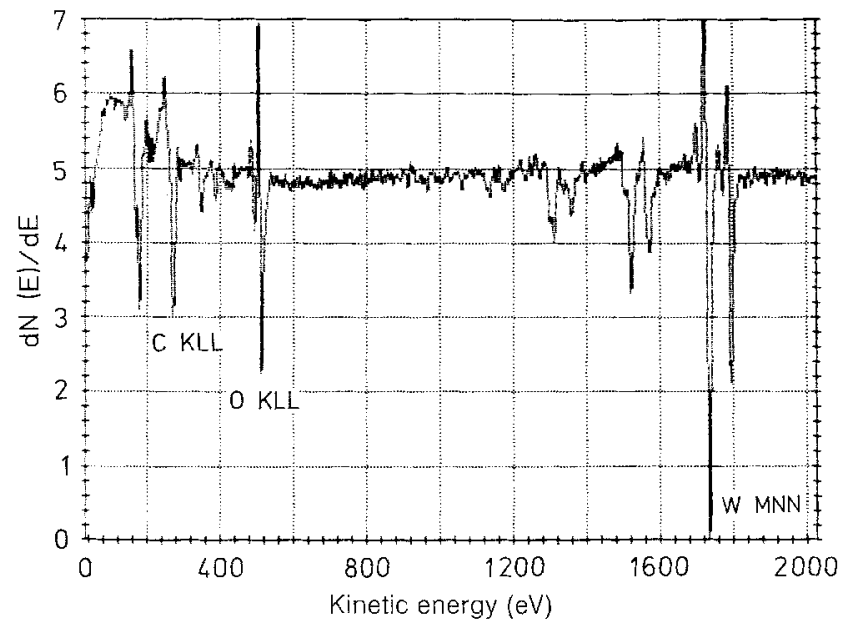

Fig. 2. Auger spectrum of STM tungsten tip surface before $\mathrm{Ar}^{+}$ sputtering

min, by calibration performed on $\mathrm{Ta}_{2} \mathrm{O}_{5}$ layers of thickness of $100 \mathrm{~nm}$ and comparison the experimental sputtering yields [6] for pure Ta and $\mathrm{W}$.

XPS measurements were done with a KRATOS 800 system. The XPS spectra were taken with $\mathrm{Mg}-\mathrm{K}_{\alpha}$ radiation, after calibration of the instrument with a $\mathrm{Cu}$ standard sample to give an elemental binding energy of $\mathrm{Cu} 2 \mathrm{p}_{3 / 2}=932.67 \mathrm{eV}$. The analyzed area was about $0.2 \mathrm{~mm}^{2}$ by a diaphragm utilization. In order to achieve reasonable quality for both the quantitative evaluation and peaks discrimination, XPS spectra of W4f, C1s and O1s needed about $15 \mathrm{~h}$ of data accumulation time with instrumental resolution $\sim 1.3 \mathrm{eV}$. The quantitative evaluation of $\mathrm{W} 4 \mathrm{f}, \mathrm{C} 1 \mathrm{~s}$ and $\mathrm{O} 1 \mathrm{~s}$ was performed with the KRATOS DS800 software.

\section{Results and discussion}

\subsection{AES measurements}

Figure 2 shows the Auger spectrum of a typical STM tungsten tip at the surface region. It reveals oxygen and carbon in addition to tungsten.

The measured Auger sputter depth profile of a tungsten tip is displaced in Fig. 3. The peak-to-peak heights of the W MNN, C KLL and O KLL Auger peaks, divided by standard sensitivity factors [7], have been plotted in atomic concentration $(\mathrm{AC})$ mode as a function of sputter time.

It can be seen that the carbon and oxygen concentrations decrease very rapidly during the first minute of sputtering. The thickness of $C$ and $O$ layers in this region was found to be $1-3 \mathrm{~nm}$, as an average over 5 measured tips. This value is comparable to that one reported by Biegelsen et al. [3] (1$5 \mathrm{~nm}$ ) and Garnaes et al. [4] (3-10 nm) for electrochemically etched oxide-covered tungsten tips studied with the TEM.

We conclude that the surface region of the tungsten tip is contaminated by carbon and oxygen arising from the preparation procedure and exposition to air. The thickness of this layer is independent of the time of exposition to air at room temperature, revealed by Auger in-depth profile measurements of $\mathrm{W}$ tips after 0.5 and $100 \mathrm{~h}$ of exposition to air, respectively.

C KLL and O KLL Auger lines have been compared before and after $15 \mathrm{~nm}$ depth sputtering of $\mathrm{W}$ tips. Figure 4

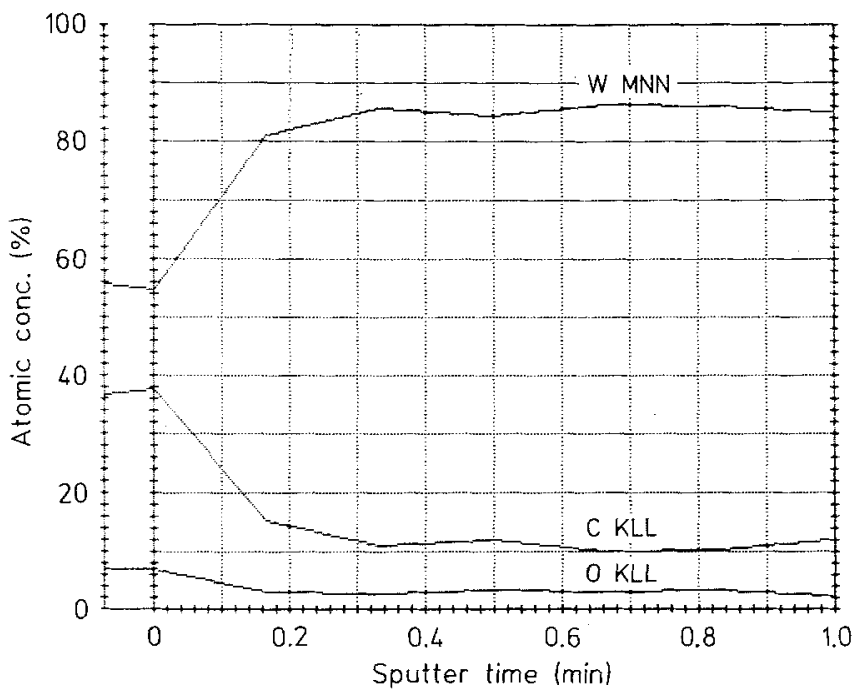

Fig. 3. Auger sputter depth profile of STM tungsten tip. Sputter rate: $4.3 \mathrm{~nm} / \mathrm{min}$

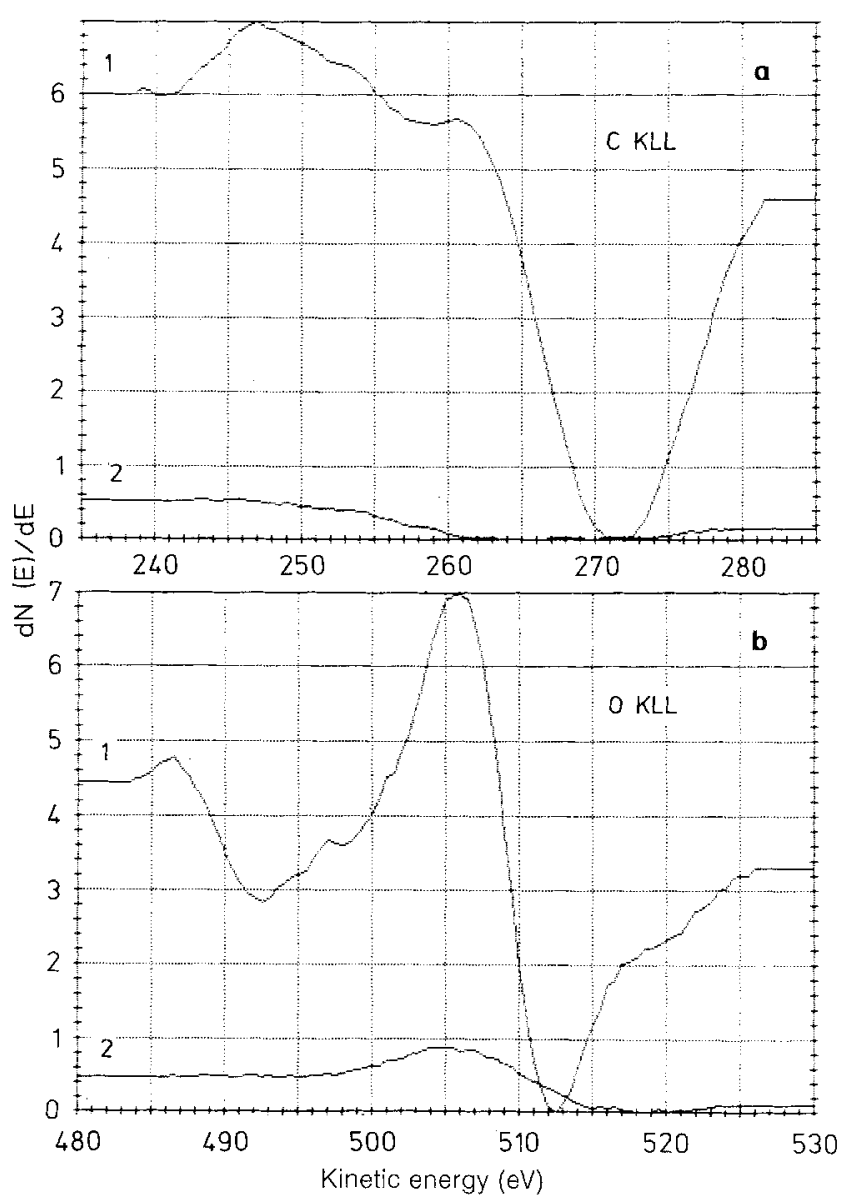

Fig. 4a, b. AES lines in the differentiated mode for a) C KLL and b) O KLL of tungsten tip before (lines I) and after (lines 2) $15 \mathrm{~nm}$ $\mathrm{Ar}^{+}$sputtering

shows the different character of carbon and oxygen contaminations in bulk and at the surface region.

The C KLL Auger spectrum peaks at 272,256 and $242 \mathrm{eV}$ suggest the graphite nature of carbon at surface region of $\mathrm{W}$ tip, as was reported by Haas et al. [8]. The shift of C KLL 

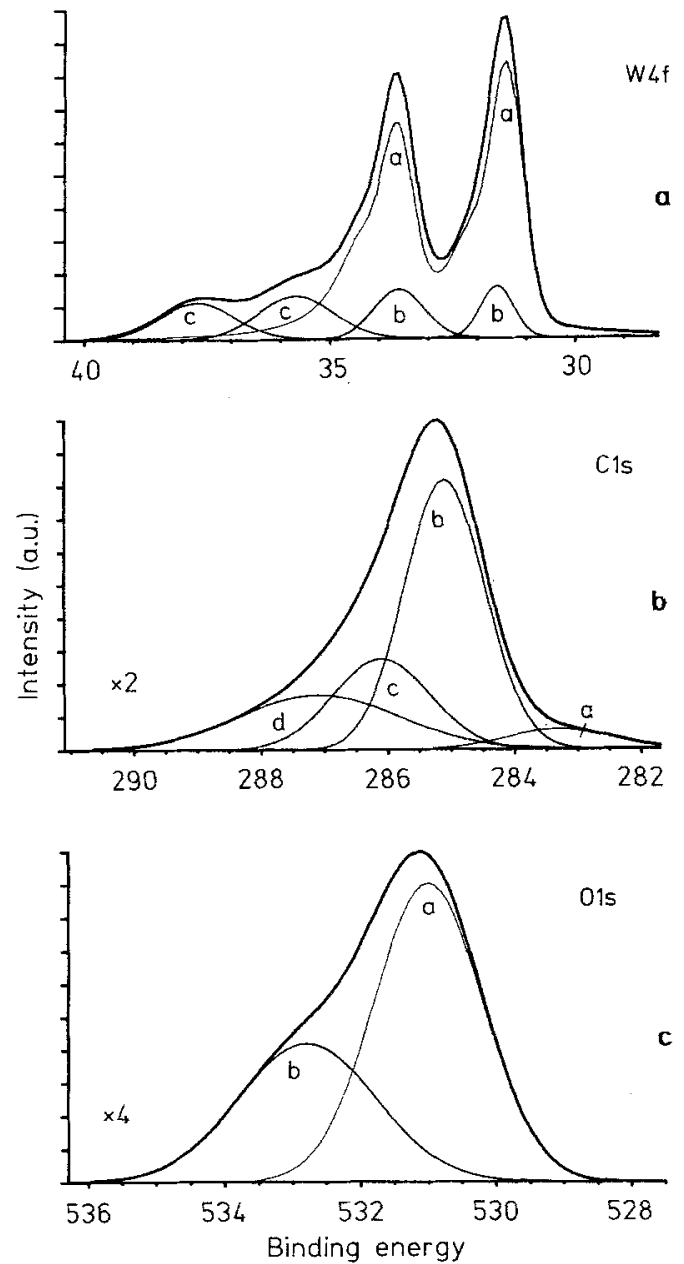

Fig. 5a-c. W4f (a), C1s (b) and O1s (c) XPS spectra of STM tungsten tip. Deconvoluted peaks are described in the graph. a $a$ : $\mathrm{W} ; b$ : WC; $c: \mathrm{WO}_{3} ; \mathbf{b} a$ : WC, $b$ : graphite; $c$ : hydrocarbon; $d: \mathrm{CO}$; c $a: \mathrm{WO}_{3} ; b: \mathrm{O}_{2} ; \mathrm{CO}$

Auger peak at $272 \mathrm{eV}$ to lower energies after sputtering and the shape of Auger lines (Fig. 4a) seem to be indicative of a carbide character of carbon in the bulk [8].

\subsection{XPS measurements}

Fig. 5 shows the XPS spectra of W4f, C1s and O1s of the STM tungsten tip.

Binding Energy (BE) of $\mathrm{W}_{4 \mathrm{f}_{7 / 2}}$ signal $(31.5 \mathrm{eV})$ was found to be close to that reported by other authors (Table 1). The quantitative evaluation and deconvolution of the W4f spectrum, taking into account Lorentzian-Gaussian contributions, revealed additional peaks at BE 35.5 and $37.5 \mathrm{eV}$ (Fig. 5a). Based on results of the fitting procedure and comparing these results with binding energies reported earlier for some tungsten compounds (Table 1), we can confirm coexisting of $\mathrm{W}, \mathrm{WO}_{3}$ and $\mathrm{WC}$ in the surface region of tungsten tips.

The complex character of the C1s spectrum is shown in Fig. 5 b. The four XPS peaks at 283.1, 285.0, 286.1 and $287.1 \mathrm{eV}$ can be related to tungsten carbide $[9,15]$, graphite [17], hydrocarbon carbon [18] and molecular adsorbed $\mathrm{CO}$ [16].

The interpretation can be based also on 3 different states of $\mathrm{CO}$ adsorption ( $\beta$ at $282.6 \mathrm{eV}, \alpha$ at $287 \mathrm{eV}$ and "virgin"
Table 1. Tungsten $4 \mathrm{f}_{7 / 2}$, carbon $1 \mathrm{~s}$ and oxygen $1 \mathrm{~s}$ binding energies $(\mathrm{eV})$ of some selected tungsten compounds

\begin{tabular}{|c|c|c|c|c|c|c|}
\hline Levels & W & WC & $\mathrm{WO}_{2}$ & $\mathrm{WO}_{3}$ & $\begin{array}{l}\text { Reference } \\
\text { standard } \\
\mathrm{Au} 4 \mathrm{f}_{7 / 2} \\
=83.8 \mathrm{eV} \\
\mathrm{C} 1 \mathrm{~s} \\
=285.0 \mathrm{eV}\end{array}$ & Ref. \\
\hline \multirow[t]{2}{*}{$\mathrm{W} 4 \mathrm{f}_{7 / 2}$} & $\begin{array}{l}31.2 \\
30.7\end{array}$ & 31.6 & $\begin{array}{l}32.5 \\
32.7\end{array}$ & $\begin{array}{l}35.5 \\
35.0 \\
35.6\end{array}$ & $\mathrm{Au} 4 \mathrm{f}_{7 / 2}$ & $\begin{array}{l}{[9]} \\
{[11]} \\
{[14]}\end{array}$ \\
\hline & $\begin{array}{l}31.8 \\
31.8 \\
33.0\end{array}$ & $\begin{array}{l}32.4 \\
32.3\end{array}$ & 34.4 & $\begin{array}{l}36.0 \\
35.9 \\
36.3 \\
36.0\end{array}$ & C1s & $\begin{array}{l}{[10]} \\
{[12]} \\
{[13]} \\
{[14]} \\
{[14]}\end{array}$ \\
\hline $\mathrm{C} 1 \mathrm{~s}$ & & 282.8 & & & $\mathrm{Au} 4 \mathrm{f}_{7 / 2}$ & [9] \\
\hline $\begin{array}{l}\text { C1s (con- } \\
\text { taminant) }\end{array}$ & & 284.4 & & & $\mathrm{Au} 4 \mathbf{f}_{7 / 2}$ & {$[9]$} \\
\hline O1s & & & 531.5 & $\begin{array}{l}531.0 \\
530.1 \\
531.0 \\
530.7\end{array}$ & $\begin{array}{l}\mathrm{Au} 4 \mathrm{f}_{7 / 2} \\
\mathrm{C} 1 \mathrm{~s}\end{array}$ & $\begin{array}{l}{[11]} \\
{[14]} \\
{[14]} \\
{[14]}\end{array}$ \\
\hline
\end{tabular}

Table 2. The evaluation of carbon, oxygen and tungsten concentration in the surface region of a STM W tip and a W sheet

\begin{tabular}{lllll} 
& \multicolumn{3}{c}{ Method Atomic concentration [\%] } \\
\cline { 3 - 5 } & & Carbon & Oxygen & Tungsten \\
\hline $\begin{array}{l}\text { Tungsten tip as } \\
\text { received }\end{array}$ & AES & $35.8 \pm 4.2^{\mathrm{a}}$ & $8.9 \pm 1.1^{\mathrm{a}}$ & $55.2 \pm 4.0^{\mathrm{a}}$ \\
$\begin{array}{l}\text { Tungsten tip } \\
\text { after sputtering }\end{array}$ & AES & $10.4 \pm 1.5^{\mathrm{a}}$ & $2.6 \pm 0.4^{\mathrm{a}}$ & $86.9 \pm 1.8^{\mathrm{a}}$ \\
$\begin{array}{l}\text { Tungsten sheet } \\
\text { as received }\end{array}$ & XPS & 36.5 & 27.8 & 35.7 \\
$\begin{array}{l}\text { Tungsten sheet } \\
\text { after sputtering }\end{array}$ & XPS & 6.7 & 18.1 & 75.2 \\
\hline
\end{tabular}

${ }^{a}$ An average value of 5 tips

at $284.8 \mathrm{eV}$ ) on polycrystalline $\mathrm{W}$ [16]. Nevertheless, the application of "virgin" state, formed at $77 \mathrm{~K}$ [16], seems to be rather doubtful in our case. However, the hydrocarbon contaminations from cleaning procedure should be taken into account.

Similar analysis for O1s spectrum (Fig. $5 \mathrm{c}$ ) disclosed the existence of O1s XPS peaks at 530.9 and $532.7 \mathrm{eV}$, referred to $\mathrm{WO}_{3}$ (Table 1) and chemisorbed $\mathrm{O}_{2}$ and $\mathrm{CO}[15,16]$, respectively.

The results of quantitative evaluation of $\mathrm{C}, \mathrm{O}$ and $\mathrm{W}$ concentrations are presented in Table 2. Unexpected high concentration of carbon, found by our XPS measurements on the W tip, can be explained by carbon monoxide adsorption from the UHV system at very long $(15 \mathrm{~h}$ ) measuring times. In order to get a better insight into this contamination, we replaced the tungsten tip by a W sheet with a large area of the same material, to eliminate the long measuring time and exposure. The electrochemical etching and cleaning procedure were the same as for W tip. 

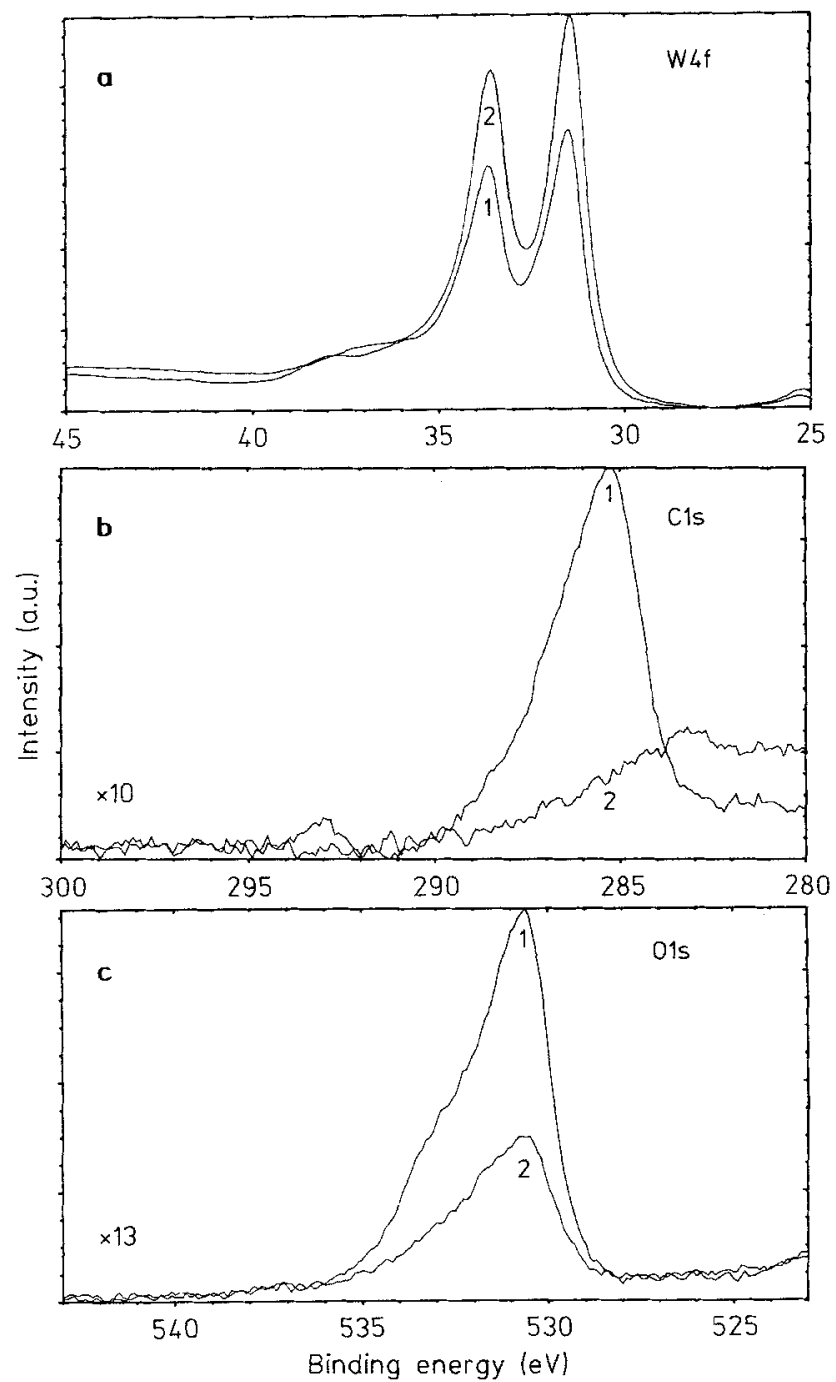

Fig. 6a-c. The comparison of W4f (a), C1s (b) and O1s (c) XPS spectra of tungsten sheet before (lines 1) and after (lines 2) $15 \mathrm{~nm}$ $\mathrm{Ar}^{+}$sputtering

Figure 6 shows the tungsten sheet XPS spectra of W4f, $\mathrm{C} 1 \mathrm{~s}$ and $\mathrm{O} 1 \mathrm{~s}$ before (lines 1) and after (lines 2) $\mathrm{Ar}^{+}$ sputtering. The XPS measurements were executed before and after $\mathrm{Ar}^{+}$sputtering of about $15 \mathrm{~nm}$ of tungsten, in order to compare results with AES data (Table 2).

$\mathrm{The}^{+} \mathrm{r}^{+}$sputtering removes oxygen, carbon monoxide, graphite and tungsten oxide resulting in a decrease of $\mathrm{O} 1 \mathrm{~s}$ peak (Fig. 6c) and W4f doublet peaks of $\mathrm{WO}_{3}$ (Fig. 6a). The tungsten carbide peak is revealed after elimination of graphite and $\mathrm{CO}$ (Fig. 6b).

The resulting concentrations of $\mathrm{C}, \mathrm{O}$ and $\mathrm{W}$ before and after sputtering are in reasonable agreement with AES data (Table 2). Preferential sputtering of oxygen in more effective $\mathrm{Ar}^{+}$sputtering procedure, used for AES measurements, could be a reason of lower tip oxygen concentration compared with the W sheet XPS analysis results.

\section{Conclusions}

The following conclusions can be drawn:

- XPS and AES techniques appear to be very useful in qualitative and quantitative analysis of surface contaminations of STM tungsten tips. This is helpful for a preliminary selection of good performance tips.

- Graphite, tungsten carbide, carbon monoxide and hydrocarbons were found as main carbon contaminations of the tungsten tip surface.

- Chemisorbed oxygen, carbon monoxide and tungsten oxide were detected as oxygen contaminations of the $\mathrm{W}$ tip surface.

- The thickness of tungsten oxide was estimated to be $1-3 \mathrm{~nm}$.

- A small concentration of carbon and oxygen in the bulk of the tip depends on impurities of the tungsten material used for tip fabrication.

Acknowledgement. The authors wish to thank Prof Dr. A. van Silfhout and Prof. Dr. H. Rogalla for their helpful discussions. The authors also would like to thank Mr. B. Otten for preparing the SEM images and Miss M. Buurman for typing the manuscript.

\section{References}

1. Kuk Y, Silverman PJ (1986) Appl Phys Lett 48:1597-1599

2. Tiedje T, Varon J, Deckman H, Stokes J (1988) J Vac Sci Technol A6:372-375

3. Biegelsen DK, Ponce FA, Tramontana JC, Koch SM (1987) Appl Phys Lett 50:696-698

4. Garnaes J, Kragh F, Morch KA, Thölén AR (1990) J Vac Sci Technol A8:441-444

5. Colton RJ, Baker SM, Driscoll RJ, Youngquist MG, Baldeschwieler JD, Kaiser WJ (1988) J Vac Sci Technol A6:349-353

6. Seah MP (1981) Thin Solid Films $81: 279-287$

7. Davis LE, MacDonald NC, Palmberg PW, Riach GE, Weber RE (1978) Handbook of auger electron spectroscopy

8. Haas TW, Grant JT, Dooley GJ (1972) J Appl Phys 43:18531860

9. Colton RJ, Rabalais JW (1976) Inorg Chem 15:236-238

10. McGuire GE, Schweitzer GK, Carlson TA (1973) Inorg Chem $12: 2450-2453$

11. Ng KT, Hercules DM (1986) J Phys Chem 80:2094-2102

12. Biloen P, Pott GT (1973) J Catal 30:169-174

13. Wagner CD (1978) J Vac Sci Technol 15:518

14. Nefedov VI, Salyn YV, Leonhardt G, Scheibe R (1977) J Electron Spectrose 10:121-124

15. Umbach E, Menzel D (1983) Surf Sci 135:199-224

16. Brundle CR (1975) Surf Sci 48:99-136

17. Hamrin K, Johansson G, Gelius U, Nordling C, Siegbahn K (1970) Phys Scr 1:277-280

18. Gelius $U$, Hedén PE, Hedman $\mathrm{J}$, Lindberg BJ, Manne $\mathrm{R}$, Nordberg R, Nordling C, Siegbahn K (1970) Phys Scr 2:7080 